\title{
ANALYSIS OF COMMUNITY CSR ACTIVITIES OF TATA CHEMICALS LIMITED
}

\section{AARTI CHOPRA}

Principal, Bhavan's College of Communication and Management, Jaipur, Rajasthan, India

\begin{abstract}
This research has been conducted to determine the measures taken by an Indian company to conduct its CSR activities. Tata Chemicals Limited is the company chosen for this research which provides community service in the regions of Gujarat, Uttar Pradesh and West Bengal. As identified, the social practices are different in these cities and thus, a certain strategy must have been followed to conduct each community service which has been obtained in this research. Interpretive research method has been used to analyse the data obtained from the employees related to company's CSR projects via primary survey. The result shows that the company has been extremely efficient in drafting CSR policies and to communicate those policies to the local public in the right context. It has helped the company to render excellent service to the society and enhancing its goodwill in the market.

KEYWORDS: CSR Activities, TATA Chemicals Ltd
\end{abstract}

Received: Jun 07, 2020; Accepted: Jun 20, 2020; Published: Jul 20 2020; Paper Id.: IJMPERDJUN2020389

\section{INTRODUCTIONs}

CSR factors and policies in India have changed significantly after it had been made mandatory in the year 2013. India is one of the first countries to have made it mandatory to adopt CSR policy for each industry operating in the market (Shira, 2020). It has been stated that the CSR programs in India can only be undertaken as a separate program which are not related to business activities. This is to say that government has made it mandatory for every business organisation to contribute towards the welfare of the society either by voluntary work or by providing financial benefits. Tata Chemicals Limited is one of the leading organisations in the country that is popular for its CSR activities (Fernandes, 2019). The contribution had been made by this organisation to develop the rural society in many interior regions of the country. Moreover, it had also contributed in protecting the wildlife forests and helped in preserving endangered species. Its spending on CSR activities gets distributed in three regions of the country, namely, Haldia in West Bengal, Mithapur in the Gujarat region and in Babrala at Uttar Pradesh. Again, there always remain a specific set of social problems that each business faces owing to the differences of opinion within the members of the society (Flache et al., 2017). It receives all kinds of threats and often their projects get sabotaged by the local members. It is important to understand the measures that an organisation takes to initiate such social events and the finances that are being used for this purpose. This research will provide basic information about the measures that are taken to make sure that social campaign remains successful.

\section{RESEARCH AIM}

The main aim of this research is to determine the measures taken by Tata Chemicals Limited to conduct successful CSR campaign.

\section{RESEARCH QUESTION}


Is it essential to follow a certain strategy while conducting a CSR activity?

\section{RESEARCH OBJECTIVE}

To find ways to improve the success rate of the CSR activities in India.

\section{LITERATURE REVIEW}

A company often contributes in CSR activities in order to promote their services to the public. It helps the organisation to create a good rapport with the government of that city which is essential to develop their operational activities. In most of the emerging countries, the government finds it difficult to manage the welfare of each section of the society (Grayson \& Hodges, 2017). This is due to financial constraints, unemployment factors and overall poverty issue. Salemink et al., (2017), stated that the introduction of a working body in rural region can solve this issue to a great extent. It not only aids in solving the employment issue but by providing all kinds of legal benefits, the government can avail financial help from these big institutions to develop the local surroundings. Moreover, the industry would also want to develop its surroundings to increase the productivity level as well.

The behaviour of the firm towards its citizens often gets noticed by the society in order to address its ability to fulfil its responsibility. This is one of the biggest steps to be taken to satisfy the customers and it helps the organisation to gain multiple stakeholders (Pino et al., 2016). A firm operating in a society has to fulfil all kinds of responsibilities so that people can meet their requirements. Under section 135, it has been stated by the CSR committee in India that the activities performed towards the society by an organisation is essential for the development of its relationship with its customers (Singla, 2018). It is a part of business that would also require extensive planning and a certain procedure to be followed to be able to successfully implement the process. The greater the amount a company spends on operational process, the greater is the revenue for a certain company. A survey conducted in the year 2010 stated that the private organisations have more involvement in the CSR activities in India than public organisation. The private entities take care of the welfare of around 20 states and union territories (Ranjan \& Tiwary, 2017).

Gereffi \& Lee, (2016), stated that the CSR activities are not just limited to the welfare of the society but it also takes care of the development of the local industries, small-scale farmers by supporting or collaborating with them in their production process. By CSR, the presence of diversified culture within the workplace is ensured. The quality of the work improves and equality is being maintained in the society as well. Moreover, it creates opportunities for children to take up education and develop their knowledge. Literacy in interior villages is a big issue in India and the development of schools and universities in interior villages can be beneficial for the organisation (Singh, 2019). Again, it is the private sector in India which had taken the initiative of 'Go Green' movement. Several well-known banks have participated in this movement and are looking to inspire others to take care of the nature as well (Rao et al., 2019).

Research \& Development is an important part of the development process. Protecting environment is never an easy process and it requires dedication and proper methodology to be able to employ effective measures in the system. However, it also comes with several challenges that each institute had faced before the application of the process. This is because the general public had shown lack of interest in taking up responsibilities to maintain cleanliness in the environment (Otto et al., 2018). Without the support of the local people it is indeed difficult to maintain the services. The communication channel is not clear between the stakeholder and the business and hence the policies are often misunderstood by general public. In addition to that, there are corruptive practices in many different sectors of a firm and it is difficult for a business to locate 
and rectify the mistakes of the firm (Hanousek et al., 2019). Most local firms do not even disclose their operational program and their actions are often considered to be suspectable due to amount of money being spent on the event.

Despite having such barriers, it can be seen that the CSR activities have been developing in the country and the major private institutions are taking initiatives to make improvement in the society. This research is going to evaluate the measures taken by the firms in addressing these issues and the relevancy of their contribution to the different sections of the society, especially the local community.

\section{RESEARCH METHODOLOGY}

\section{Research Philosophy}

This research will adopt interpretive approach, as the information obtained from the survey will be used to interpret the possible result for this research. It is essential to understand the effectiveness of the measure taken for the development of the community. This research will gather all the social information that are relevant and will be used to find the possible solution to the problem.

\section{Research Approach}

This research will be using the inductive approach as a set of observation from the gathered data is being used to obtain the result. This research will provide a new theory regarding the factors that are associated with the development of this social process.

\section{Research Strategy}

This research will adopt survey questionnaire strategy to obtain the data for analysis purpose. This research is going to gather information about the measures and systems adopted by Tata Chemicals Limited to conduct their social movement. In that case, information is needed to be gathered from the employees and official working within the organisation.

\section{Time Horizon}

This research will adopt cross-sectional time frame data which means that this research is focused only on one particular time frame, which is the financial year 2019-20 and the result could vary in the future.

\section{Data Collection and Analysis}

Since, this research is using survey method, the data collection that is to be used is primary data collection method and the sample size chosen for this research is 90 people who are the employees of the company working on CSR projects. Also, this research requires information that is current and relevant to the present situation. Therefore, it would require the experience and resources used by the members of the organisation at this present situation.

\section{ANALYSIS AND DISCUSSIONS}

The questions were asked mostly based on the individual experience on working on social services programs. It gathers information about the issues, setting, practices and other relevant factors that can affect the performance of an organisation. Although $18 \%$ of them had prior experience of community service, yet it would be a challenge for most of them. The employees had prior experience over its services towards communities. 
The experience of the employees suggests that they have a fair idea about the proceedings of the community service and they knew the kind of issues that they might face in their process. About $36 \%$ of the employees stated that social issues are common in social service procedure. Communication and lack of social interest is one of the biggest challenges that one faces while committing themselves in a social service. Many people in interior villages are not interested over improving the condition of the society and hence, it is difficult to convince them about the issues and policies. Even political parties also play a big role in the success of a community service. A difference in opinion about political assistance had been found, which suggests that all the information is not shared with different sections of employees. This shows non-transparency in the process of community service. On the other hand, many organisations had to take permission to use a certain portion of a land to set up their camp or invite common people for the campaign. So, top officials had to have a good rapport with political members but this information are often not revealed to different section of employees due to company policies.

The lack of transparency within the management is again highlighted from the fact that $34 \%$ of the employees stated that they are not provided with full information by the management. Many employees are often just instructed to a portion of the job and the management does not bother to provide them with full information. Most of these employees had to undertake laborious jobs such as collecting or distributing the service materials. Often, then do feel deprived about the whole operational process and they start to doubt that their contribution might not get recognised by the management. Although it does not have any impact over the CSR performance but it does create a difference in the team which can be harmful in the long run.

All the decisions and strategies are being set up by the management only with the help of the colleagues. A sense of unity had been observed as about $50 \%$ of the employees stated they worked collaboratively to design the operational process. This is because, each and every person is needed to be present during the distribution of the job role and discuss the possible materials required by them like pen, paper, food, water and other useful materials to conduct the operational process. It was also found that each of them had various opinions about the total spending over the whole project. This is due to the fact that the sample size consists of different section of employees who have very little idea about the spending requirement for organising an event. They only knew about the spending on the raw materials and operational expenses which is the reason the answer being more diverse in terms of average spending. It is expected that the community service does take above 1 Crore Indian rupees for full-fledged service.

On being asked which promotional process is more effective, $34 \%$ of the employees think that the banners and posters is the most effective process. This is because, in the interior regions, most of the people are not financially equipped to possess a separate television set of their own. Moreover, the availability of smart phone and internet service in the interiors is very low and thus, the use of social media or electronic media might not be effective (Mounika et al., 2018). Instead, banners and posters are straight away visible to all the members of the community and hence, this is the most suitable way to share the news of social event to each member of the community. Although, few of them might think that promoting the news in social media or television might boost the goodwill of the company. The news of the social service will get spread out to the whole country which can help the organisation to earn additional revenue (Qing, et al., 2020). Most of the employees seem to be confident about the success of the project. About $34 \%$ of the employees think that they have adequate materials to successfully complete this social occasion. An additional back-up stock is kept as well for emergency purpose. So, it would not be a problem in dealing with the requirement of the social service. 
Social and political hindrances will come in the process of any good deed. However, it is important to ensure that the right measures had been taken to implement the process properly. It can be seen that the organisation is very particular about sharing of the information. Most of the information is not revealed to a major section of the employees. This is because the management knows that it can cause leakage of information which can hamper the whole program. In any project, knowledge sharing had been an important part and it has been found that it is not necessary to share information with all the members of the team. It is important to have shared only the relevant information about the job for which an individual had been entrusted. It increases the effectiveness of the process as people can concentrate on the job with a free mind as they do not have to take responsibility for the outcome of the project. This is one way, to conduct CSR activities in India despite so many obstacles that could come in the form of social and economic hindrances.

\section{CONCLUSIONS}

Conducting a CSR activity is important for any private organisation to establish its presence in the market. For past few years, it has been a legal mandate too. Tata Chemicals Limited is one of the strongest names in the Indian business market and it is because of their noble deeds. Conducting a program in a society is never easy as it needs to satisfy a diversified section of the community. So, it does require a strategy in place to conduct the program. It can be seen that the main strategy of Tata Chemicals Limited is to maintain secrecy in their system owing to extreme external influence. It means that people working in the industry only had the information surrounding their work, while the rest of it is kept away from them. It not only reduces the chances of information leakage but also allows a person to concentrate only on their job. It increases the efficiency of the work level and makes their campaign successful. This is how Tata Chemicals Ltd., had been successfully conducting social service campaigns across India and build up a reputation for themselves in the market.

\section{REFERENCES}

1. Fernandes, K., (2019). Top 20 Indian Companies for CSR in 2019. The CSR Journal.

2. Flache, A., Mäs, M., Feliciani, T., Chattoe-Brown, E., Deffuant, G., Huet, S., \& Lorenz, J. (2017). Models of social influence: Towards the next frontiers. Journal of Artificial Societies and Social Simulation, 20(4).

3. Gereffi, G., \& Lee, J. (2016). Economic and social upgrading in global value chains and industrial clusters: Why governance matters. Journal of business ethics, 133(1), 25-38.

4. Grayson, D., \& Hodges, A. (2017). Corporate social opportunity!: Seven steps to make corporate social responsibility work for your business. Routledge.

5. Hanousek, J., Shamshur, A., \& Tresl, J. (2019). Firm efficiency, foreign ownership and CEO gender in corrupt environments. Journal of Corporate Finance, 59, 344-360.

6. Mounika, N., Nagamani, G., \& Sreekanth, M. (2018). Modeling Rural Connectivity Requirements in India with Case Studies. Journal of Engineering Sciences, 9(1).

7. Otto, A., Hornberg, A., \& Thieken, A. (2018). Local controversies of flood risk reduction measures in Germany. An explorative overview and recent insights. Journal of Flood Risk Management, 11, S382-S394.

8. Pino, G., Amatulli, C., De Angelis, M., \& Peluso, A. M. (2016). The influence of corporate social responsibility on consumers' attitudes and intentions toward genetically modified foods: evidence from Italy. Journal of Cleaner Production, 112, 2861 -2869. 
9. Qing, K. J., Kee, D. M. H., Soon, J. C. T., Hui, C. K., Singh, A., Kurniawan, O. E.,... \& Sin, L. G. (2020). The Impact of Employee Satisfaction, Organizational Commitment, Job Performance and Teamwork as the Success Factors in FedEx: A Study of FedEx's Employees in Malaysia. International journal of Tourism and hospitality in Asia Pasific, 3(2), 48-56.

10. Ranjan, R., \& Tiwary, P. K. (2017). A comparative study of CSR in selected Indian public and private sector organisations in globalisation period: A research finding. International Journal of Emerging Research in Management and Technology, 6(6).

11. Rao, M. D. B., Prasad, R. S., \& Revathy, J. (2019). A Study on Green Banking Services Initiated by Various Public and Private Sectors Banks in India. Journal of the Gujarat Research Society, 21(16), 1180-1188.

12. Salemink, K., Strijker, D., \& Bosworth, G. (2017). Rural development in the digital age: A systematic literature review on unequal ICT availability, adoption, and use in rural areas. Journal of Rural Studies, 54, 360-371.

13. Shira, D., (2020). Corporate Social Responsibility in India. India Briefing.

14. Singh, R. (2019). Scenario of Indian Rural Market: Importance, Challenges, Opportunities and Emerging Trends. research journal of social sciences, 10(3).

15. Singla, A., (2018). Corporate Social Responsibility (CSR) as Per Companies Act, 2013. Tax Guru. https://taxguru.in/companylaw/corporate-social-responsibility-csr-companies-act-2013.html.

16. Ramu, C., and C. Vethirajan. "Customers Perception of CSR Impact on FMCG Companies-An Analysis." IMPACT : International Journal of Research in Business Management(IMPACT : IJRBM) 2019: 39-48

17. Roman, Donald L. Amorosol\& Francis. "CSR Perceptions on Consumers'repurchase Intention: Comparison of Japan, China, and The United States." International Journal of Economics, Commerce and Research (2017): 1-6

18. Yadav, Satbir, and Sunil Budhiraja. "CSR and Sustainability Reporting in India: The Way Forward" International Journal of Human Resource Management and Research (2019): 89-100

\section{APPENDIX}

\section{Survey Questions}

1. In what kind of social setting have you worked in previously?

a) Community-service.

b) Environmental service.

c) Local health organisation.

d) NGOs.

2. Have you ever faced any kind of social issues while working in previous social series?

a) Yes.

b) No.

c) This is my first time.

3. What do you think are the factors that often restrict the operations of a social practice?

a) Political interference.

b) Lack of involvement of common people. 
c) Lack of service materials.

d) Communication gap.

4. Have you ever experienced internal mis-management during you service time within the organisation?

a) Things are absolute in order inside.

b) There is no communication among the peers

c) Occasional arguments arise over the procedure.

d) This is my first time.

5. Is the whole program and planning initiated by the management only?

a) Yes.

b) No.

c) Do not have clear idea.

d) We all worked coordinatively.

6. What is the average estimate of finances required for this project?

a) 50 Lakhs.

b) 50-75 Lakhs.

c) $\quad 75-100$ Lakhs.

d) Above 1 Crore.

7. Have you taken political support for this project?

a) Yes.

b) No.

c) Cannot Say.

8. How are you promoting your service to the community?

a) Banner and posters

b) Newspaper and TV.

c) Social Media.

d) Promotional campaign in desired location.

9. Do you feel the resources obtained are adequate for the service?

a) It is adequate.

b) More or less adequate. 
c) Back-up stock is present.

d) It is not adequate.

10. Finally, do you see this campaign to be successful?

a) Yes.

b) No.

c) I do have some reservations.

d) It will not be successful.

\section{Survey Results/ Figures}

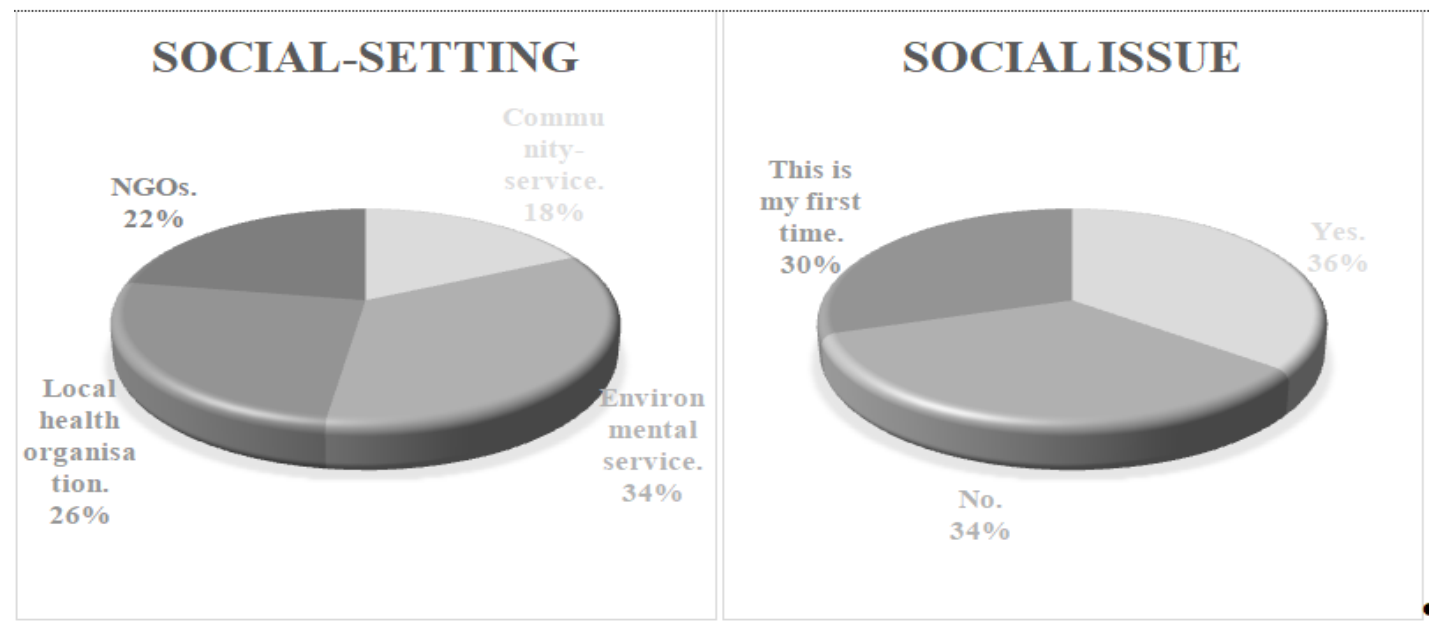

Figure 1

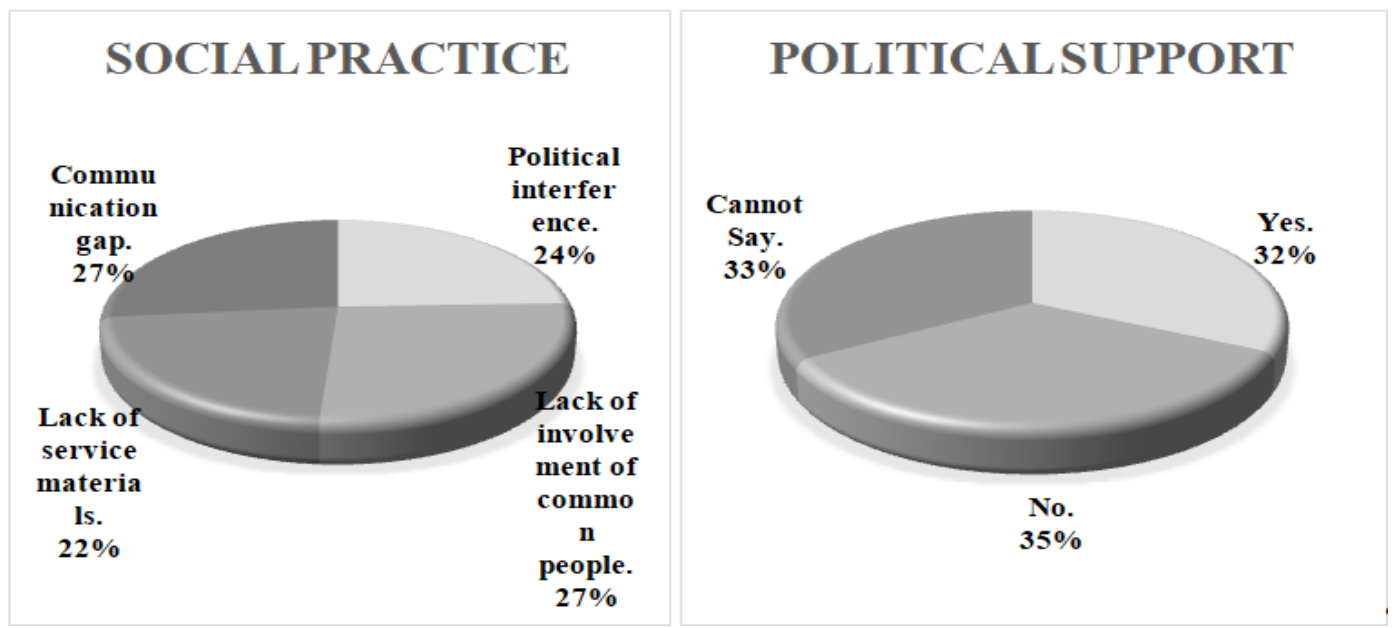

Figure 2 


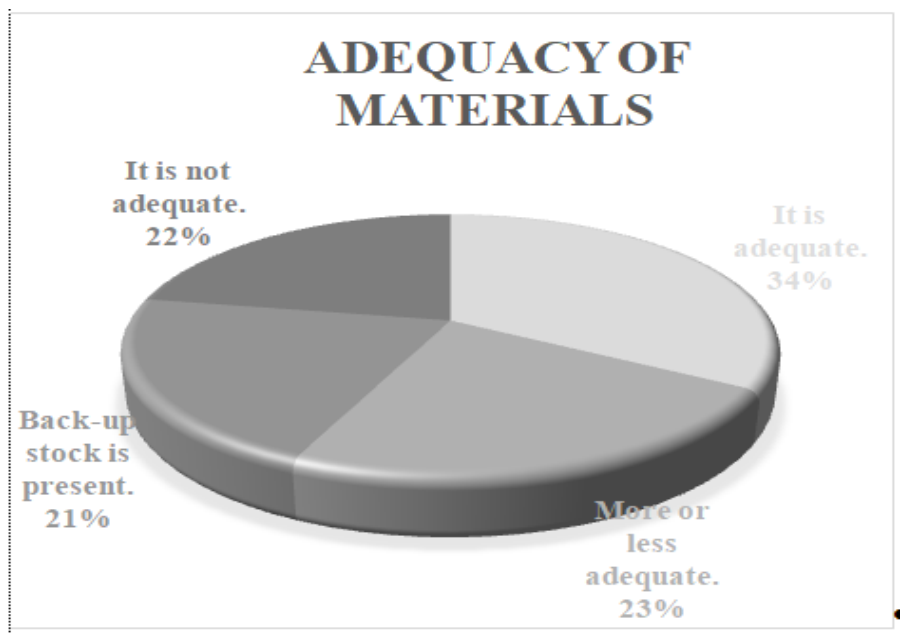

Figure 3

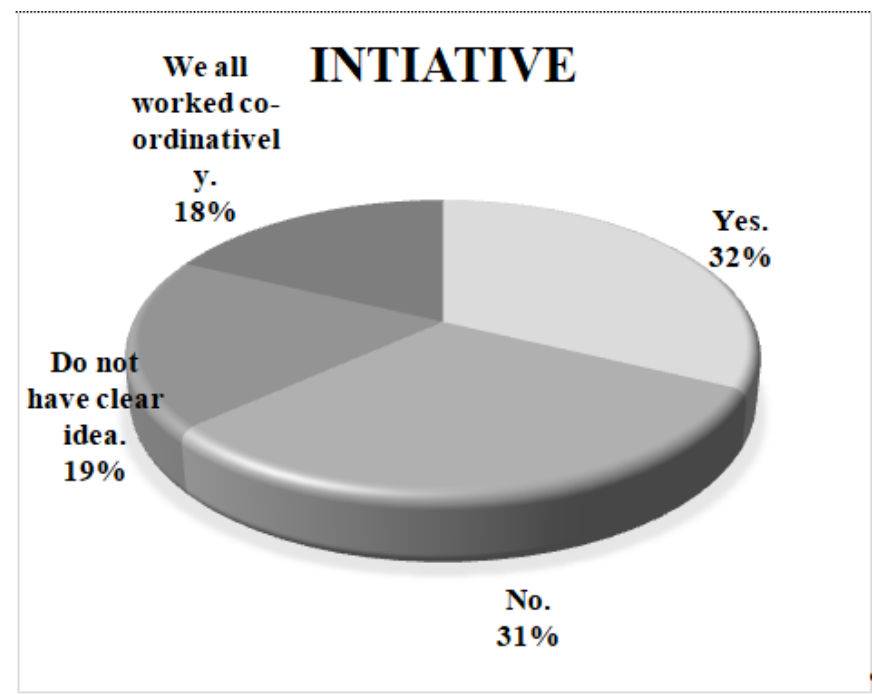

Figure 4

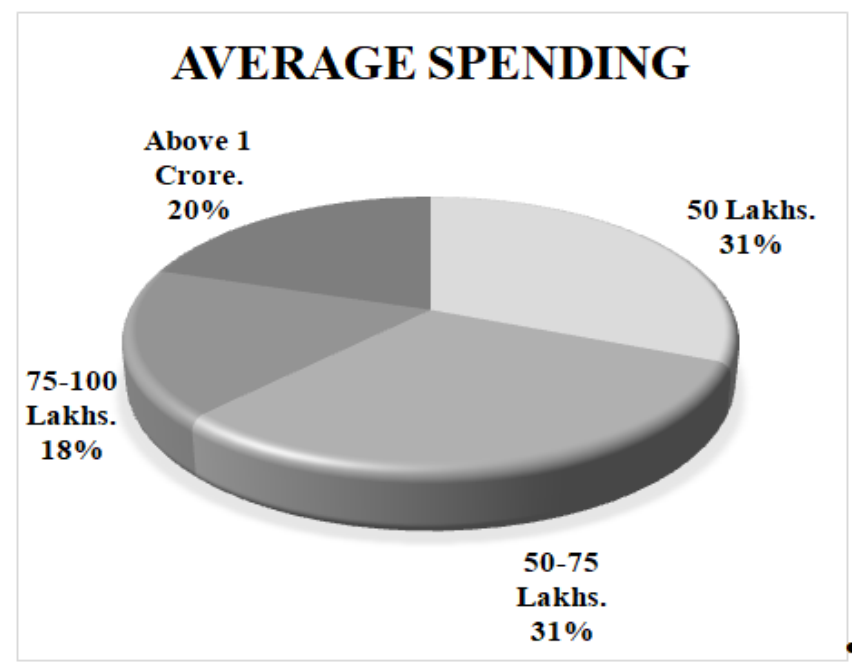

Figure 5 


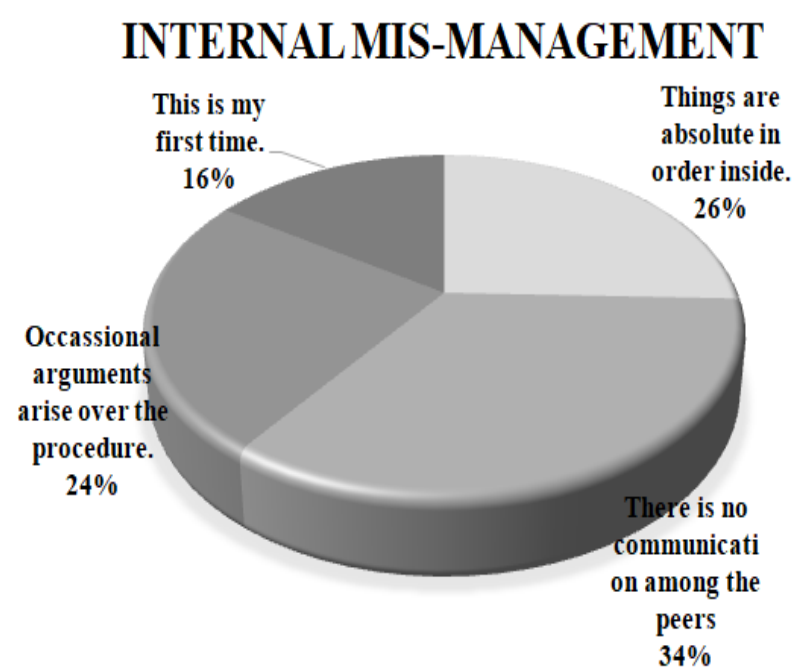

Figure 6 